\title{
Effective policy communication: Targets versus instruments
}

by Francesco D'Acunto, Daniel Hoang, Maritta Paloviita and Michael Weber

No. 147 | MARCH 2021

\section{WORKING PAPER SERIES IN ECONOMICS}

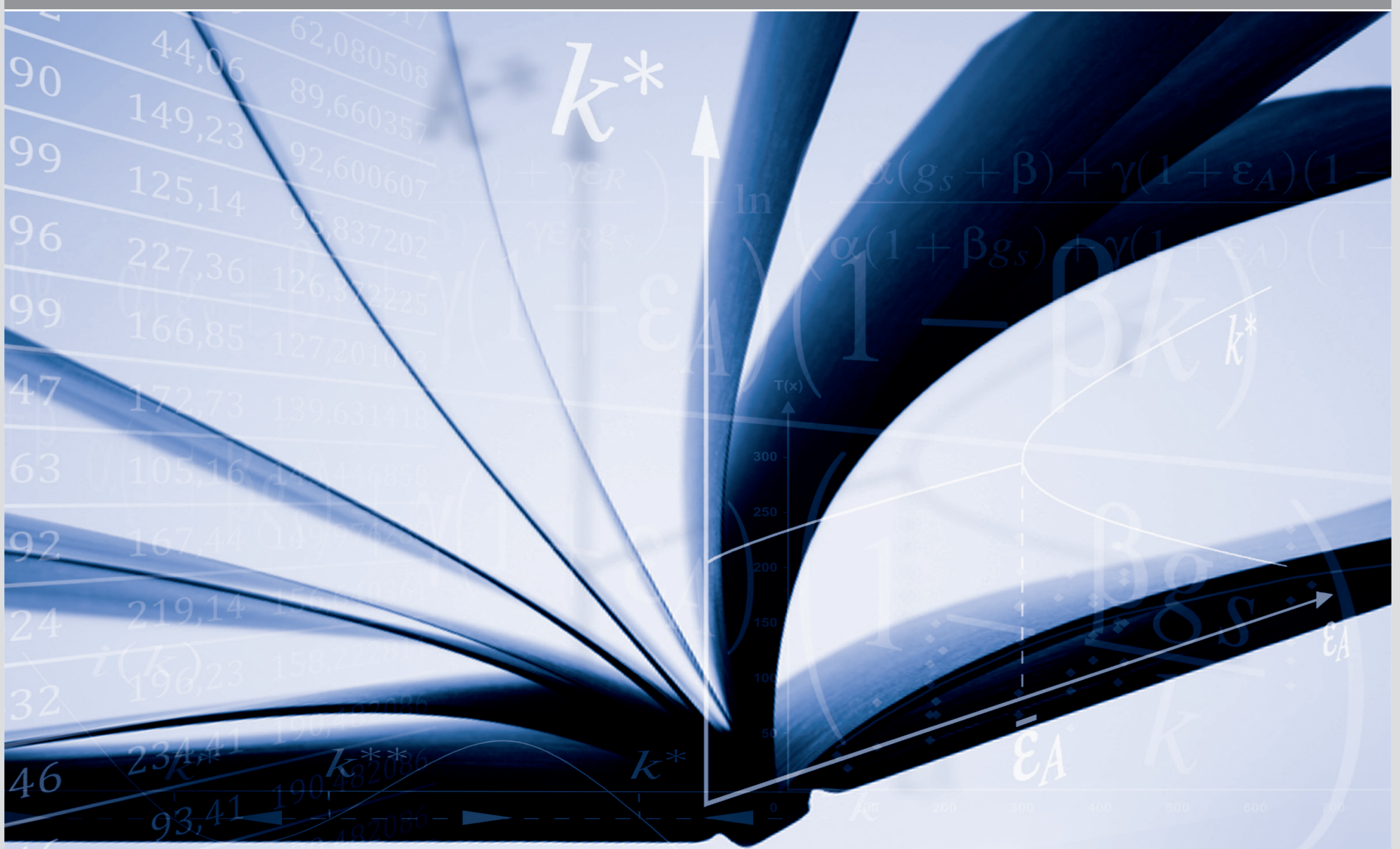




\section{Impressum}

Karlsruher Institut für Technologie (KIT)

Fakultät für Wirtschaftswissenschaften

Institut für Volkswirtschaftslehre (ECON)

Kaiserstraße 12

76131 Karlsruhe

KIT - Die Forschungsuniversität in der Helmholtz-Gemeinschaft

Working Paper Series in Economics

No. 147, March 2021

ISSN 2190-9806

econpapers.wiwi.kit.edu 


\title{
Effective Policy Communication: Targets versus Instruments* \\ Francesco D’Acunto, ${ }^{\dagger}$ Daniel Hoang, ${ }^{\ddagger}$ Maritta Paloviita, ${ }^{\S}$ and Michael Weber $\mathbb{1}$
}

This version: October 2020

\begin{abstract}
Communication targeting households and firms has become a stand-alone policy tool of many central banks. But which forms of communication, if any, can reach ordinary people and manage their economic expectations effectively? In a large-scale randomized control trial, we show that communication manages expectations when it focuses on policy targets and objectives rather than on the instruments designed to reach such objectives. It is especially the least sophisticated demographic groups, which central banks typically struggle to reach, who react more to target-based communication. When exposed to target-based communication, these groups are also more likely to believe that policies will benefit households and the economy. Target-based communication enhances policy effectiveness and contributes to strengthen the public's trust in central banks, which is crucial to guarantee the credibility of their policies.
\end{abstract}

JEL classification: D12, D84, D91, E21, E31, E32, E52, E65

Keywords: Behavioral Macroeconomics, Heterogeneous Beliefs, Limited Cognition, Expectations Formation, Household Finance.

${ }^{*}$ This research was conducted with restricted access to data from the Finnish Defence Forces and Statistics Finland. The views expressed here are those of the authors and do not necessarily reflect the views of the Bank of Finland, Finnish Defence Forces, or Statistics Finland. We thank the project coordinator at Statistics Finland, Valtteri Valkonen, for his help with the data and very insightful comments. We also thank Marios Angeletos, Yuriy Gorodnichenko, and several seminar and conference participants. We gratefully acknowledge financial support from the Thyssen Foundation and the Becker-Friedman Institute at the University of Chicago. Weber also gratefully acknowledges financial support from the University of Chicago Booth School of Business, the Fama Research Fund at the University of Chicago Booth School of Business, and the Fama-Miller Center.

${ }^{\dagger}$ Carroll School of Management, Boston College, Chestnut Hill, MA, USA. e-Mail: dacuntof@bc.edu

${ }_{\ddagger}^{\ddagger}$ Department for Finance and Banking, Karlsruhe Institute of Technology, Karlsruhe, B-W, Germany. e-Mail: daniel.hoang@kit.edu

$\S$ Bank of Finland, Helsinki, Finland. e-Mail: Maritta.Paloviita@bof.fi

IBooth School of Business, University of Chicago, Chicago, IL, USA and NBER. e-Mail: michael.weber@chicagobooth.edu. 


\section{Introduction}

The ECB needs to be understood by the markets that transmit its policy, but it also needs to be understood by the people whom it ultimately serves. People need to know that it is their central bank, and it is making policy with their interests at heart.

ECB President Christine Lagarde, 2019

Over the past decade or so, the FOMC has enhanced its communication practices to promote public understanding of its policy goals, strategy, and actions, as well as to foster democratic accountability.

Fed Vice Chair Richard Clarida, 2019

Policy communication has become an important measure in central banks' toolbox to manage household and firms' expectations directly, especially in times of low interest rates, when the scope of traditional monetary policy measures transmitted through financial markets and intermediaries is limited. This novel policy tool has challenged one of central banking's tenets - the technicality of its communication, which was so essential to the practice of monetary policy that, in the words of Karl Brunner, "the esoteric nature of [central banking] is (...) revealed by an inherent impossibility to articulate its insights in explicit and intelligible words and sentences" (Brunner (1981); see also, e.g., Goodfriend (1986) and Greider (1989)). Using communication as a policy tool poses an unprecedented dilemma to central banks around the globe: which forms of communication, if any, can reach ordinary households, who do not understand and are uninterested in deciphering obscure policy statements (see, e.g., Blinder (2009), Binder (2017), Andre, Pizzinelli, Roth, and Wohlfart (2019), Coibion et al. (2019))?

In this paper we draw on insights from macroeconomics, marketing, and social psychology to study which forms of communication can affect households' expectations and their interpretation of policy in line with the aims of policy makers. Inspired by recent work in macroeconomic theory (Angeletos and Sastry (2018)), we ask in particular if central banks should focus their communication on the instruments they adopt to reach policy targets (e.g., provide guidance about the path of interest rates) or if instead they should only discuss the policy targets themselves, as in Dr. Draghi's claim that the ECB would do "whatever it takes to preserve the Euro, and believe me, it will be enough." 1

To tackle this question empirically, we designed a randomized information-provision experiment on a representative sample of Finnish men for whom we observe several

\footnotetext{
${ }^{1}$ This form of target communication satisfies the criteria of being "simple, crisp, and constructively imprecise" Angeletos (2020) proposes.
} 
demographic characteristics, including a test-based measure of cognitive abilities. In this experiment, all subjects read policy statements coming from the same medium and the same source - the official twitter account of the Governor of the Bank of Finland, Dr. Olli Rehn. What varied across conditions was whether the (real) tweets subjects read consisted of target- or instrument-based policy communication. The target communication tweet stated: "The European Central Bank will do whatever is necessary to minimize the financial damage to citizens caused by the corona crisis" (tweeted on March 20 ${ }^{\text {th }}, 2020$ ). The instrument communication tweet stated: "New EUR750 billion Pandemic Emergency Programme (PEPP) launched by the European Central Bank" (tweeted on March $\left.18^{\text {th }}\right) .^{2}$

Figure 1 previews our findings. We overlay two histograms reporting the distribution of answers to whether respondents thought that the policies proposed by the ECB to overcome the COVID-19 crisis would not benefit households at all (1), would benefits households a lot (7), and the levels in between. Before answering, respondents were randomly exposed to instrument-based communication (black histogram) or target-based communication (red histogram): The target-communication histogram is shifted to the right relative to the instrument-communication one, which means that agents exposed to target communication were systematically more likely to believe that ECB policies would benefit households rather than agents exposed to instrument communication.

This qualitative fact begets the question of how target and instrument communication compare in managing agents' quantitative expectations, which is the ultimate goal of central banks. To answer this question, we elicited households' numerical income expectations both before and after the randomized information provision in a within-subject experimental design. ${ }^{3}$

\footnotetext{
${ }^{2}$ As we discuss in more detail below, our design also includes a control group of subjects who read a tweet by Dr. Rehn that also referred to a time of crisis in Finnish history but that was unrelated to economic policy or current events: "The January engagement created the spirit of Winter War 80 years ago. Memories do not live, but they do" (tweeted on January $20^{\text {th }}, 2020$ ). This groups aims to capture any effects of the mere reading of information as well as being primed with a sense of crisis into subjects.

${ }^{3}$ As we discuss in more detail below, to avoid asking the same question twice, which could raise concerns about demand effects (Coibion et al. (2020); D'Acunto (2020a)), we first asked for a point estimate and then elicited a full probability distribution based on the wording of the New York Fed Survey of Consumer Expectations (see, e.g., Crump et al. (2020)).
} 


\section{Figure 1: Target versus Instrument Communication}

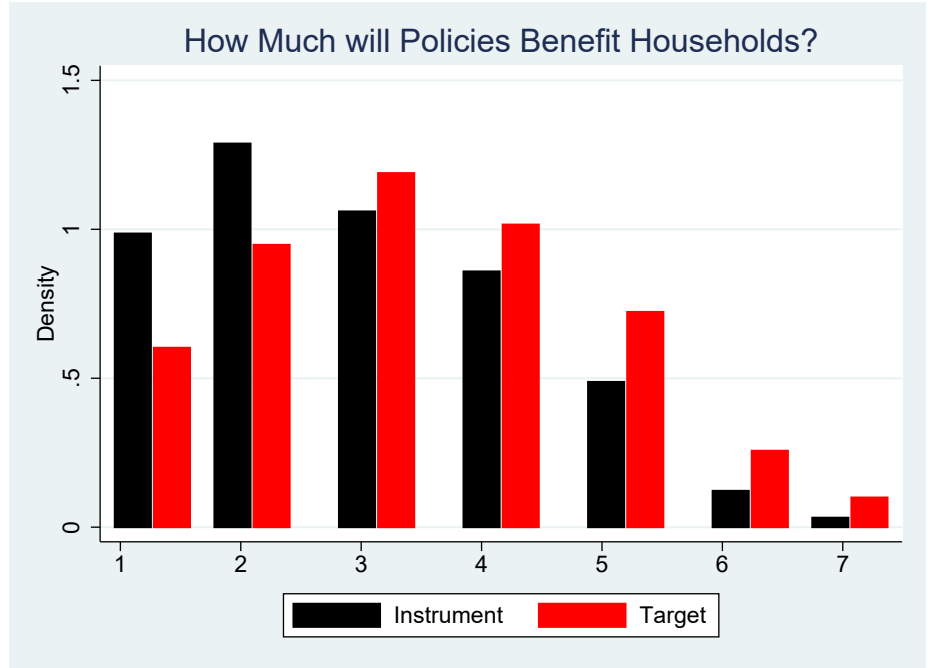

This figure plots the shares of respondents who think that policies will not benefit households at all (1), will benefit households a lot (7), or expectations in between these extremes, separately for respondents randomly exposed to target and instrument communications. Target communication was a tweet by Bank of Finland Governor Olli Rehn that the "The European Central Bank will do whatever is necessary to minimize the financial damage to citizens caused by the corona crisis." Instrument communication was a tweet by Bank of Finland Governor Olli Rehn that the "New Euro 750 billion Pandemic Emergency Programme (PEPP) launched by the European Central Bank." We measure normalized IQ using data from the official military entrance exam in Finland. We elicit whether policies benefit households on a seven-point Likert scale with 7 being policies benefit households extremely. We fielded the survey in June 2020.

We confirm the results about respondents' qualitative beliefs documented in Figure 1 when respondents update their quantitative income expectations: Target communication increases average monthly gross income expectations between EUR 70 and EUR 80 relative to the control group in the raw data as well as conditional on a rich set of observables such as age, marital status, income, employment status, location, education level, as well as direct measures of economic preferences, liquidity constraints, and financial literacy. The size of this effect, which is fully driven by (costless) target-communication adoption, aligns with recent fiscal policy measures to support household income such as the "80-Euro tax bonus" introduced in Italy in 2014, whose cost amounts to about EUR 9.5 billion per year. ${ }^{4}$

Contrary to target communication, exposing subjects to instrument communication does not results in any statistically or economically significant forecast revision of household-income expectations, relative to the control group. Note that, because none of the treatments or the control text contain any references to household-level

\footnotetext{
${ }^{4}$ Because the bonus is granted based on a nominal household-income threshold, the number of recipients changes across fiscal years.
} 
income, a mechanical anchoring of expectations to externally induced values cannot drive our findings. Moreover, experimenter demand effects (De Quidt, Haushofer, and Roth (2018)) - subjects behaving in line with what they think is the experimenters' hypothesis - are an unlikely explanation for our results, because each subject only faces one treatment condition. To guess the experimenters' hypothesis, subjects should be aware of the recent economic-theory work by Angeletos and Sastry (2018) and the debate summarized by Angeletos (2020), which, despite the relevance of this work in academic and policy circles, seems largely implausible.

After documenting that target and instrument communication have different ability to manage average individual expectations, we assess whether the effects are heterogeneous across subjects. This exercise is motivated by the fact that a major concern of policy makers is that traditional policy communication does not reach less sophisticated households, who might find it too costly to gather and process technical information. Recent empirical work echoes this concern by documenting that agents below the top of the distribution by cognitive abilities have more pessimistic expectations and are in general less responsive to economic policies (D'Acunto et al. (2019a,b, 2020)). Limited cognition has also been described by recent theoretical macro research as a relevant friction to the transmission and effectiveness of monetary policy (Farhi and Werning (2019), Gabaix (2020), Woodford (2018), Angeletos and Sastry (2018)).

Being able to test for the effects of providing communication to those agents who are harder to reach is crucial not only to understand the mechanisms of the effects of policy communication on beliefs and choice, but also from a policy perspective: If we found strong effects of target communication on harder-to-reach consumers, the recent efforts by central banks around the world to reach out more to such consumers might be justified. If, instead, the effects were stronger for consumers who already access economic and policy information from other sources, perhaps such efforts might be less worthwhile.

We split our sample by median cognitive abilities as measured by the Finnish Defense Forces (FDF) through entry-week tests during the compulsory military service. For men with below median levels of IQ, we find that target communication increases income expectations by more than EUR 90 per month, which is $38 \%$ higher than the effect we estimate for subjects with above median IQ. The size of the treatment effect increases to EUR 160 when conditioning on observables that plausibly correlate with IQ. In this case, the effect we estimate is about three times as large as the conditional treatment 
effect for high-IQ men. Ultimately, target communication is not only more effective than instrument communication in managing the expectations of the average consumer but it helps especially with managing the expectations of the least sophisticated groups in the population.

An obvious channel that might explain why target communication is easier to understand is the cost of processing information. Keeping constant the exposure to some form of economic information, target communication might be easier to understand and process (intensive margin of communication) and hence might generate a stronger reaction, especially on the part of the least sophisticated consumers.

At the same time, a complementary channel involves the ability of target communication to reach the least sophisticated more (extensive margin of communication), irrespective of their understanding of such communication. To assess the role of this channel, we consider separately subjects who were already aware of the ECB policies discussed in Dr. Rehn's tweets before participating in our experiment and subjects who were unaware. For target communication, we find that the treatment effect on income expectations further increases among subjects that were unaware of the policy measure before the tweet relative to the overall sample, and especially for men below the median of the IQ distribution. Instead, irrespective of policy awareness and IQ, we find small effects of communicating about instrument communication on income expectations.

The last heterogeneity dimension we consider is consumers' prior income-change expectations. If low-IQ subjects with more pessimistic expectations - the demographic group that the central bank really wants to reach to manage their expectations upward - are indeed those who react most strongly to target communication, we should find the largest treatment effect in this subsample. And, indeed, the treatment effect of target communication is almost three times as large in this subsample than in the full sample. Target communication has instead a more muted effect on the beliefs of those with above-median prior income change expectations. This latter result ensures that treating households with target communication does not turn them into overoptimistic or extrapolative agents. It also ensures that a mechanical mean reversion of expectations does not drive our results.

Overall, our results indicate that monetary policy communication can be a successful policy tool to manage ordinary households' expectations, but this effectiveness is enhanced when central banks emphasize the targets and aims of their policies rather than the specific 
policy measures with which they want to reach such aims.

Our experiment has merely scratched the surface of the role of the communication styles and rhetoric used by policy institutions on economic agents' beliefs. Additional research is necessary to better understand other features that might contribute to the effectiveness of target communication, such as the role of different types of media. Given the high level of unawareness of economic policy among households even in our experiment, central banks need to understand which media can deliver their target communication messages to the broader population to maximize its effectiveness.

\section{A. Related Literature}

Over the last decades, a dramatic shift in the openness and the clarity of central bank communication has occurred. Yet, traditionally, most of the communication has been focused on financial markets, professional forecasters, and possibly the media which might then transmit the news to households and firms (Blinder et al. (2008) and Blinder and Krueger (2004)). Ehrmann and Fratzscher (2009), Lange et al. (2003), Swanson (Swanson), and Neuhierl and Weber (2019) indeed show that increased transparency and communication does shape financial market expectations of future interest rates and reduce financial volatility. Yet, Blinder (2009) argues that "It may be time for both central banks and researchers to pay more attention to communication with a very different audience: the general public" and continues "effective communication with the general public will surely have to be very different, in both content and style, than effective communication with the financial markets. It seems to me that, to date, few central banks have taken this task very seriously".

Haldane and McMahon (2018) discuss evidence from the UK that increased communication with the public has not increased the general knowledge of the pillars of monetary policy making since 2001. Haldane et al. (2020) argue theoretically that successful communication with the broader public should rely on "Explanation, Engagement and Education". D'Acunto et al. (2020) show in observational data that European households only update their inflation expectations following simple communication but not following complex communication. Lamla and Vinogradov (2019) run household surveys in the days before and after FOMC policy meetings and do not find that households on average change their beliefs about future inflation or interest rates. 
Their results are consistent with the fact that many households do not follow monetary policy announcements in their day to day life.

To understand the possible power of direct communication with households, a series of recent papers rely on lab experiments and randomized control trials in surveys. Kryvtsov and Petersen (2020) conduct a lab experiment and find providing information of past interest rates has the strongest effect on the volatility of price and expenditure forecasts of individuals, contrary to forward-looking announcements. Binder and Rodrigue (2018), Armantier et al. (2016), Coibion et al. (2019), and Coibion et al. (2020) show in survey experiments that providing simple information about current and future inflation rates results in large forecast revisions of households but that relying on the media to transmit the information might be less effective because of a general level of distrust towards the media. These results suggest that direct communication with households can be effective to manage their expectations once central banks are able to pierce the veil of ignorance. So far, we have little knowledge which types of communication are effective in reaching households. We contribute to this literature by comparing the effectiveness of targetversus instrument-based communication following the theoretical framework of Angeletos and Sastry (2018) and Angeletos (2020).

\section{Data}

Our analysis uses three micro datasets that include individual-level information on economic expectations and cognitive abilities, as well as administrative information on household-level income.

\section{A. Data on Cognitive Abilities}

Finland has general conscription for men, which means all Finnish men between the ages of 18 and 60 are liable for military or non-military service. The share of men who do non-military service is only about $3 \%$ of all men who start military service. ${ }^{5}$ Within the first weeks of the mandatory military service, Finnish men typically around the age of 19-20 have to participate in a series of tests. The FDF administer these tests and use the results to select candidates for possible officer training. Because ranking well in the IQ

\footnotetext{
${ }^{5}$ Please see https://puolustusvoimat.fi/en/conscription for these and additional details.
} 
test provides a set of advantages in terms of quality of training and access to elite social networks, men have an incentive to perform as well as possible on the test (Grinblatt et al. (2011)).

The cognitive-ability test consists of 120 questions that focus on three areas visuospatial, mathematical, and verbal. The FDF aggregates those scores into a composite measure of cognitive abilities, which we label collectively as IQ. The FDF standardizes IQ to follow a stanine distribution. Stanine (STAndard NINE) is a method of scaling test scores on a 9-point standard scale with a mean of 5 and a standard deviation of 2 , approximating a normal distribution. The respondents with the lowest $4 \%$ of test scores are at least 1.75 standard deviations from the mean and are assigned a standardized IQ score of 1 , and the $4 \%$ with the highest test scores are assigned a standardized IQ score of 9 . Hence, most of the mass of our observations is around the median bin, whereas the extreme bins account for only a small part of the sample. We have test results for all participants from 1982 until 2001.

Finland is a homogeneous country in terms of cultural background and opportunities. Access to education, including college education, is virtually for free. The country is also racially homogeneous (Grinblatt et al. (2011)). These features make the Finnish setting a desirable laboratory because our measures of IQ are unlikely to proxy for differences in cultural or environmental factors (D'Acunto et al. (2018)), which individuals could manipulate, but are more likely to reflect differences in innate abilities across individuals.

\section{B. Survey Data on Expectations}

In the Spring of 2020, we designed a customized survey in cooperation with Statistics Finland. Statistics Finland recruited the overall sample which was stratified by age and education levels to ensure a large overlap with our data on IQ which we could not use in the stratification. We fielded the survey in early June 2020 and the survey was in the field for two weeks. The structure of the survey consists of three parts. ${ }^{6}$ In the first part of the survey, we first elicit a few basic information including proxies for financial constraints, financial portfolios, annual income in 2019, expected changes in average monthly gross household income in 2020 compared to 2019, subjective expectations for current and future unemployment rates and mortgage rates and expected inflation over the next twelve

\footnotetext{
${ }^{6}$ The Online Appendix contains the detailed questions of the survey.
} 
months.

The second part of the survey consists of a randomized information provision experiment. Given that some of the questions post treatments resemble questions we had asked before treatments and survey participants often are alienated when being asked identical questions twice and to alleviate concerns about survey demand effects (De Quidt et al. (2018)), we introduce the experimental part of the survey with a short introductory text: "We have just a few more questions. But before you give us your responses, we would like to provide you with some information. We will subsequently ask you again about your expectations again. We are interested to see if this information will change your expectations or not. There is no right or wrong reaction: Whether this information changes your expectations or not is solely determined by your opinions, and any reaction or non-reaction is right as long as it reflects what you truly believe. The European Central Bank that is responsible for monetary policy in the whole Eurozone including Finland and the Finnish Financial and Insurance Supervisory Authority have recently implemented several policy measures."

We then randomly split our sample in three groups. All three groups receive information from the same sender, Governor Rehn from the Bank of Finland, and from the same medium, Twitter. Our design therefor mimics settings in lab experiments keeping constant the sender and medium and only varying the content of the true tweets. The first group is a control group that does not receive any information related to monetary policy communication. Given we fielded the survey during the global COVID-19 pandemic, we provided the control group with the actual tweet by Rehn on January $20^{\text {th }} 2020$ that "The January engagement created the spirit of Winter War 80 years ago. Memories do not live, but they do". The Target communication treatment arm received the tweet from March $20^{\text {th }} 2020$ that "The European Central Bank will do whatever is necessary to minimize the financial damage to citizens caused by the corona crisis". And finally, the Instrument communication treatment arm received the tweet from March $18^{\text {th }} 2020$ that "New EUR750 billion Pandemic Emergency Programme (PEPP) launched by the European Central Bank".

The third part of the survey consists mainly of follow-up questions that everyone receives. We first ask how much they think these policy actions will benefit households on a seven-point Lickert scale. We then again elicit expectations for inflation and income change expectations using a full probability distribution like the New York Fed Survey of 
Consumer Expectations (see Armantier et al. (2016)) and point estimates for mortgage rates and unemployment rates. The remaining questions elicit financial and economic literacy and grocery duties within households following D'Acunto et al. (2019, 2020).

\section{Data on Income from Tax Returns}

We also have access to administrative income and debt data for all Finnish full-time residents at the end of each calendar year through Statistics Finland. The data contain information on individuals' labor and business incomes, received and paid income transfers, as well as overall household taxable assets and liabilities. The information is collected from underlying sources across various agencies (Tax Administration, National Institute for Health and Welfare, Statistics Finland, Kela), administrative registers, and statistical repositories.

\section{Descriptive Statistics}

In terms of sample selection, we start out with 2,627 survey responses that we can merge with the data on cognitive abilities. We drop 141 observations because the response on income in the survey was more than EUR 100,000 higher than the registry-based income data: This gap might indicate that households reported their annual income in the survey rather than their average monthly income, which is what we had asked for. We asked for average monthly income because we also elicited changes in average monthly incomes in 2020 relative to 2019 both before and after the information treatment. None of our results change qualitatively or quantitatively if we do not drop these observations. Our final working sample contains 2,486 Finnish men for whom we observe survey responses, test-based measures of cognitive abilities, as well as administrative data from the tax authority. Out of those, 868 participants are in the control condition, 799 are in the target communication group, and 819 are in the instrument communication group.

Table 1 contains the descriptive statistics of the variables we use. We winsorize all continuous variables at the 1 and 99 percent levels. On average, survey participants expected their average monthly income to fall by about EUR 90 in 2020 relative to 2019, they average monthly income was EUR 4,900, and their average age was 40. Forty five percent are married, 5.5\% unemployed at the time of the survey, and about two thirds have kids. Most of the respondents live in urban areas. About $46 \%$ has a college degree 
and almost the whole sample declares being in charge of financial decisions for their households. In terms of financial literacy, $65 \%$ answer a compounding question correctly. About two thirds have a rainy day fund and less than one third $(28 \%)$ had heard about the information we provided in the experiment beforehand.

Table A.1 in the online appendix provides the same descriptive statistics separately across treatment groups and shows that the survey treatment condition assignment was indeed orthogonal to all demographic observables.

\section{The Effects of Target vs. Instrument Communi- cation}

In this section, we describe the effects of target and instrument communication about central-bank policies on agents' qualitative and quantitative economic expectations. The subsequent section focuses on understanding which groups react more than others to these forms of communication based on heterogeneity in terms of cognitive skills and other demographic characteristics.

\section{A. Qualitative Beliefs about Policy Effectiveness}

As a first step, we consider agents' qualitative expectations to provide motivational evidence that is not affected by dimensions such as numeracy or the ability to think about probabilities (D'Acunto et al., 2020).

Both information treatments relate to the same policy interventions, i.e. those implemented by the ECB to overcome the negative economic shock due to the COVID-19 pandemic. This application is relevant in that it lets us assess the effectiveness of communication at a time in which communication by central banks is an important policy tool. At the same time, none of our results are due to peculiarities of the COVID-19 crisis: because both forms of communications refer to the same policy interventions at the same point in time, comparing the effects across the two information treatments washes away any component of agents' reaction due to specific features of the COVID-19 crisis.

Figure 1 in the introduction shows our results for qualitative expectations. We overlay two histograms, each of which reports the distribution of answers to whether respondents think that the policies proposed by the ECB to overcome the COVID-19 
crisis will not benefit households at all (1), will benefits households a lot (7), and the levels in between. The black histogram refers to respondents who were randomly exposed to instrument communication and the red histogram to those exposed to the target communication. The shape of the target-communication histogram resembles that of the instrument-communication histogram, but is shifted to the right: Subjects exposed to target communication believe that ECB policies will benefit households systematically more than respondents exposed to instrument communication. ${ }^{7}$ To assess the magnitude of this effect, we can consider the differences in the mean of each distribution. ${ }^{8}$ The average response in the target group is 3.29 , whereas it is only 2.82 for the instrument-communication group. The difference across these averages $(0.47)$ corresponds to more than $30 \%$ of the standard deviation of the distribution of this answer in the full sample.

Consistent with our argument that qualitative expectations are important to study because they are not affected by numeracy or subjects' understanding of probabilities, in Figure A.1 of the Online Appendix we show that the patterns in Figure 1 hold quite similarly when we compare the post-treatment expectations of subjects above and below the median IQ in the population. Irrespective of the level of their cognitive abilities, subjects exposed to target communication react more (and similarly) in terms of their qualitative expectations regarding the positive effects of central bank's policies on the country's households income. As we document below, target communication is instead more effective in managing the quantitative expectations of lower-IQ subjects than higherIQ subjects.

\section{B. Quantitative Beliefs about Household Income Change}

We move on to exploit the within-subject nature of our design and estimate the within-subject change in quantitative income expectations after the experimental manipulation relative to before (e.g., see D'Acunto (2020a)). Specifically, we compare the within-subject change in income expectations for subjects in each of the target and instrument communication treatments to the within-subject change in income

\footnotetext{
${ }^{7}$ Note that we have only elicited qualitative expectations after administering the experimental conditions, which is why we focus on the average cross-sectional differences across subjects rather than on within-subjects expectations updating.

${ }^{8}$ Not, though, that the numerical scale from 1 to 7 is not continuous and attaches integer values to 7 ranks in a Likert scale.
} 
expectations for subjects in the control condition, in a standard difference-in-differences identification strategy. To this aim, we estimate the following linear specification:

$$
\left(\mathbb{E}_{\text {posterior }}^{i}-\mathbb{E}_{\text {prior }}^{i}\right) \Delta \text { income }=\alpha+\beta_{j} \times \text { Treatment }_{j}+B \times \mathbf{X}+\varepsilon_{i}
$$

where $\left(\mathbb{E}_{\text {posterior }}^{i}-\mathbb{E}_{\text {prior }}^{i}\right) \Delta$ income is the within-individual quantitative income forecast revision from before to after the information treatment, Treatment $_{j}$ is a dummy for whether the subject is in the target- or instrument-communication treatment relative to the control group, ${ }^{9} \mathbf{X}$ is a vector of control variables including age, square of age, marital status, log of income, employment status, urban-rural classification, a dummy for whether the participant lives in Helsinki, a college dummy, a dummy for whether the participants shops for groceries, as well as direct measures of economic preferences, liquidity constraints, and financial literacy.

Table 2 reports the difference-in-differences estimates for the target-communication treatment (columns (1)-(2)) and the instrument-communication treatment (columns (3)-(4)). Odd columns report the univariate estimates, whereas even columns report the multivariate estimates that partial out the set of demographic characteristics listed in the column to the left. We find that target communication increases average monthly gross income expectations by EUR 74 in the univariate estimate and EUR 82.7 in the multivariate estimate. The fact that the size of the estimated treatment effects increases in the multivariate analysis even though we control for important determinants of economic expectations should not come as a surprise: the treatment conditions are perfectly randomized and hence subjects' demographic characteristics do not correlate with them.

To assuage the size of this effect, we can note that it aligns with the size of recent fiscal policy measures to support household income in the Euro area. For instance, consider the "80-Euro tax bonus" introduced in Italy in 2014, which hands out checks of EUR 80 per household member - the same size of income-expectations increase we estimate in our setting. The bonus measure costs about EUR 9.5 billion per year in Italy. ${ }^{10}$ Another way to gauge the size of the effect is to compare the average forecast revision to the average prior estimate on expected changes in monthly income in 2020 relative to 2019 . The

\footnotetext{
${ }^{9}$ The control group also reads a tweet by Dr. Rehn about surviving a crisis period, but not related to the current crisis and without discussion about policy. In this way, potential effects deriving by reminding subjects of crises are absorbed by the updates of the control group.

${ }^{10}$ Because the bonus is granted based on a nominal household-income threshold, the number of recipients changes across fiscal years.
} 
multivariate estimate of EUR 82.7 corresponds to more than $88 \%$ of the average expected drop in monthly income (see Table 1): Through a costless change in communication style, the expected income losses during a crisis period are almost completely offset.

Columns (3)-(4) of Table 2 show that exposing subjects to instrument communication barely leads to any forecast revision of household-income expectations, relative to the control group. In terms of size, the multivariate estimate is EUR 38, i.e. more than $50 \%$ smaller than the estimated multivariate treatment effect for target communication. Also, we cannot reject the null that this estimated treatment effect equals zero at any plausible level of statistical significance.

The (non-)result on the effect of instrument-based communication is also important because it shows that our results are not driven by forcing agents to read a piece of information and then asking them about it. This concern, which is sometimes raised as a limitation of information-treatment experiments in economics, is barely relevant here, because we are comparing two instances in which subjects were similarly asked to read a piece of information but to which they reacted differently. It is not the act of reading information by itself that makes agents react, but the type of information agents read is crucial to communication's effectiveness to manage beliefs.

\section{Anchoring and Demand Effects: A Concern in Our Setting?}

Information treatments like the one we propose can raise concerns about anchoring effects, that is, by providing subjects with a number in the information treatment, subjects might converge their numerical expectations to such number that acts as a numerical anchor. The scope for anchoring is minimal in our setting for at least three reasons. First, we not only study quantitative expectations, but also qualitative expectations, which by definition do not display anchoring effects (e.g., see D'Acunto et al. (2020)). Second, one of our treatments - the target-based communication treatment - includes no mentions of any numbers and is in fact the treatment that produces the largest effects on beliefs updates. Finally, when we consider quantitative income expectations we ask about households' income, whereas the instrument-based communication treatment refers to an aggregate policy amount of several billion Euros for the whole European continent. The scales of these numbers are completely off and hence anchoring has no scope.

Demand effects are a second issue that might arise in a within-subject experimental 
designs like ours. Demand effects consist of the possibility that subjects guess the hypotheses the experimenters want to test and align their behavior to such hypotheses to please the experimenters, even though they would have not have aligned their behavior in a setting in which they were not observed by experimenters. Demand effects are also unlikely to be relevant for us, because each subject only faces one treatment condition. To guess the experimenters' hypothesis, subjects should be aware of the recent economic-theory work by Angeletos and Sastry (2018) and the debate summarized by Angeletos (2020), which, despite the relevance of this work in academic and policy circles, seems largely implausible.

\section{Heterogeneous Effects of Target Communication}

Our results so far unveil that communication that focuses on policies' targets - in our application, reducing the pernicious effects of the negative economic shock caused by the COVID-19 pandemic - rather than instruments - in our application, the PEPP programare more effective in managing agents' qualitative and quantitative expectations.

The main motivation to use direct communication as a policy tool is the need of reaching out to demographic groups that traditional central bank communication would not target directly - non-expert households. Because of the high degree of technicality, non-expert households might find it too costly to gather and process traditional centralbank press releases or other forms of communication about central banks' policies, such as articles in specialized newspapers. Advocates of new forms of communication by central banks thus motivate this proposal with the need to reach out not only to experts but also to less sophisticated consumers. For instance, in the words of the former governor of the Bank of England, Mr. Carney: "When you look at what we put out (...) expert audiences read them, understand, digest, and respond to them. That's true, but that's not the way to communicate with the general public, and it's not a sustainable form of communicating in a world that has had enough experts." 11

In our context thus a natural question to ask is whether the differential effects of target and instrument communication are heterogeneous in the cross section: If target communication was especially effective in managing the expectations of less sophisticated

\footnotetext{
${ }^{11}$ See the transcript of the Wall Street Journal's Central-Bank Chiefs' Discussion in Frankfurt, November 2017.
} 
agents its adoption by central banks would be even more compelling, because sophisticated agents might be already reached by the existing technical communication to financial markets and operators. Otherwise, the question of which forms of communication can reach the least sophisticated agents in the population would remain open.

\section{A. Agents' Sophistication: Cognitive Abilities}

To proxy for sophistication, we consider subjects' cognitive abilities, which we can uniquely observe in our data. Earlier research has documented that test-based cognitive-ability scores help explain individuals' understanding of, processing of , and acting on information about economic policies (D'Acunto et al. (2019a,b, 2020)). Recent theoretical work in macroeconomics has also modeled limited cognition as a relevant friction to the transmission and effectiveness of monetary policy (Farhi and Werning (2019), Gabaix (2020), Woodford (2018), Angeletos and Sastry (2018)).

As discussed in the data section, we observe a direct measure of cognitive abilities based on the entry tests during the compulsory military service for all our subjects. We split our sample based on the median level of cognitive abilities (IQ) in the population, and we repeat our baseline estimation of the treatment effect of target communication on belief updates separately for subjects below the median and above the median by IQ.

This analysis is motivated by the raw-data distributions of the posterior beliefs about income changes for subjects exposed to different forms of communication for subjects above and below the median IQ in the population (see Figure A.2 in the Online Appendix), for which the differential effect of target communication over instrument communication on beliefs appears to be larger for low-IQ subjects than high-IQ subjects.

Table 3 reports the results for this test. Columns (1)-(2) refer to the subsample of subjects below the median IQ in the population. For this subsample, the size of the estimated treatment effect of target communication ranges from EUR 95 in the raw data to EUR 163.6 conditional on observables. In both cases we can reject the null of no treatment effect at standard levels of significance. Comparing these estimates with those in columns (1)-(2) of Table 2 (EUR 75 and 82.7, respectively) reveals that the size of the estimated treatment effect is between $22 \%$ and $98 \%$ larger in the subsample of men below median IQ, relative to the average subject in the sample. The treatment effect of target communication is thus substantially larger for the least sophisticated half of the 
population in terms of cognitive abilities.

Not only is the effect of target communication especially large for subjects with below median IQ, but in fact we fail to estimate statistically significant effects for subjects with above median IQ (columns (3)-(4)), even though the point estimates are not negligible (EUR 63.4 and 53.4, respectively).

These results support the possibility that target communication is especially effective in managing the expectations of the least sophisticated agents in the population, which might be exactly those groups central bankers aim to reach when using communication as a policy tool (Grinblatt et al. (2011)).

\section{B. Extensive vs. Intensive Margin of Information Provision: Awareness of Central Banks' Policies}

The results by cognitive abilities raise an additional question: Why do less sophisticated subjects respond more to target communication than instrument communication, even though both forms of communication refer to the same policy and hence to the same ultimate objective?

On the one hand, target communication is undeniably easier to understand for less sophisticated agents, because it does not require any knowledge or understanding of technical terms, economic mechanisms, or the mechanics of monetary policy. It does not even require any numeracy skills, which instead are needed to assess the scope of policy instruments when they are described by central banks. ${ }^{12}$ Therefore, conditional on exposing all agents to some form of information, target communication might have a stronger effect on agents' expectations because its easier processing and intelligibility provides more information to them (intensive margin of information). In an extreme case, if instrument communication was completely unintelligible to some agents, providing these agents with instrument communication would have no effect on their beliefs at all because it would be equivalent to providing them with no information whatsoever.

A complementary channel for the different effects of target and instrument communication involves the extensive margin of information provision: Because of the

\footnotetext{
${ }^{12}$ Of course, easier intelligibility does not necessarily translate into stronger reaction. To obtain a reaction, agents need to trust that the central bank will be able to implement the policy instruments needed to reach the target, and such trust might very systematically across agents with different levels of sophistication. For an empirical analysis of this point, see D'Acunto et al. (2020).
} 
simplicity of its content, target communication might be more likely to be covered by traditional media and social media. To the extent that less sophisticated agents attend more to these sources of information rather than to technical central-bank statements, which seems plausible, the likelihood that less sophisticated agents are exposed to any form of information would be higher under target communication than instrument communication. By construction, information experiments like ours cannot test for this extensive margin directly unless they included some form of cost of acquiring information and assumed that attending to different sources of information in the field implied paying different (cognitive) costs on the part of agents that are meaningfully captured by the experimental cost scheme (e.g., see Fuster et al. (2018)).

At the same time, our setting does allow for an indirect test for whether the extensive margin of information might have a role above and beyond the effect of the intensive margin. Specifically, we can exploit the fact that we elicited subjects' awareness of the information provided by the experimental treatments before they entered the experiment, which we elicited after the experimental treatments were administered. In this way, we can compare the reaction of agents who were already aware of the information, i.e. for whom the extensive margin of information has no scope, to the reaction of agents who were not aware of the information, i.e. for whom the treatment provided both an extensive and intensive margin of information. ${ }^{13}$

Table 4 reports the results for repeating our baseline analysis for the subset of subjects who reported that they were not aware of the policies, and hence for whom the treatment provided both an extensive and intensive margin of information.

For target communication, we find that the treatment effect on income expectations is large and significant for subjects who were unaware of the policy measure before the experiment (columns (1)-(2)). Comparing the size of the estimated coefficients with those for the full sample, which also includes subjects to whom the treatment provided no extensive margin of information (see columns (1)-(2) of Table 2), we find that the effect of target communication on expectations for the group exposed to both margins is about $37 \%$ higher than the effect for the full sample. Based on the arguments discussed above, we interpret this (indirect) test as suggestive that target communication is likely to have

\footnotetext{
${ }^{13}$ Note that if an agent was exposed to the information but does not recall such exposure or did not understand the information at all, they would respond that they were not aware of the information before the experiment. This case fits our interpretation: As long as the agent is not aware that he/she was exposed to information, the treatment affects them at both the extensive and intensive margins.
} 
effects on both the extensive and intensive margins of information provision.

Turning to instrument communication, columns (3)-(4) of Table 4 also have interesting implications regarding the margins of information provision: even when we focus on the set of agents that was exposed to not information at all before the experiment, instrument communication has only a small effect on their beliefs - the points estimate of the effect is positive but declines once we absorb demographic characteristics, and we cannot reject the null that the information treatment had no effect on these subjects' expectations. Under the lens of the arguments discussed above, these results seem to suggest that instrument communication provides neither a substantial intensive margin nor a substantial extensive margin of information.

In the rest of Table 4, we further focus on the subsamples of subjects who were not aware of any information about the ECB policies before the experiment and who have lower sophistication as captured by belonging to the bottom half of the population by IQ. We consider this split because in conditional summary statistics we find that awareness of policies as well as attendance to difference sources of information about economic policies before the experiment does not correlate significantly with IQ once we absorb other demographic characteristics in our representative sample (see the even columns of Table A.2 in the Online Appendix). For this reason and because Table 3 documents a stronger effect of target communication for subjects with lower IQ, we thus assess whether the effects of target communication are especially large for agents who were unaware of the ECB policies before the experiment and have lower levels of IQ. And, indeed, we find that the point estimate of the effect is more than 30\% larger for this subset of subjects (column (6)) relative to all unaware subjects (column (2)) and about $70 \%$ larger than the effect on the average subject exposed to target communication (column (2) of Table 2). Instead, even when focusing on unaware and low-IQ subjects, instrument communication does not appear to be able to manage expectations enough to reject the null of no effect whatsoever statistically.

\section{Effects Across the Distribution of Prior Beliefs About Household Income Change}

The last heterogeneity dimension we consider is the sign and size of subjects' incomechange beliefs prior to the experimental treatment, which one could interpret as subjects' 
pessimism or optimism about future household income when they entered the experiment. This dimension is important, because certain demographics tend to hold systematically more pessimistic expectations about their households' income than others, whether in good or in bad times (D'Acunto et al. (2020)).

Because managing consumers' expectations upward in times of crisis such as the COVID-19 crisis of our experimental setting is an especially important objective of central banks and an important reason to consider communication a policy tool, we investigate whether target communication is able to manage the expectations not just of less sophisticated subjects, but especially of the less sophisticated subjects with the most depressed priors about their future households' income change. In Table 5, we propose our heterogeneous analysis after splitting the subsample of subjects below the median IQ in the sample in two additional groups based on their priors regarding their own households' income change over the following twelve months.

We find that the treatment effect of target communication is almost three times as large in this subsample than for the average agent in the sample (see columns (1)-(2) of Table 5). For those above the median based on prior beliefs, we fail to document a statistically significant effect of target communication. Even though the estimated coefficients are negative and their size is not negligible, the lack of statistical significance and the difference in size of the coefficients in columns (2) and (4), i.e., EUR 229 and EUR -161 per month, reassures us against the possibility that this heterogeneity test is only capturing a mechanical mean reversion of expectations after the experimental treatment.

Ultimately, these results suggest that target communication, contrary to instrument communication, might be especially effective in managing the expectations of consumers whose beliefs about future household income are more depressed during periods of economic crisis.

\section{Conclusion}

Our large-scale randomized control trial shows that monetary policy communication can help central banks manage ordinary households' expectations, and especially the expectations of the least sophisticated and unaware households, as long as such communication focuses on policy targets and aims rather than on the specific policy measures with which central banks want to reach such aims. 
Our work paves the way for more research in several directions. First, studying in more detail which the styles and rhetoric policy institutions, and not only central banks, can use to effectively manage the beliefs of different groups of economic agents is an important and vastly open area of research for scholars in economics, marketing, social psychology, and rhetoric, and could produce interdisciplinary work across these areas (e.g., see D'Acunto (2020b)). Moreover, understanding which types of media can have different effects on different agents would be important to both the theoretical and practical design of effective economic policies.

Even more relevant would be to understand whether policy makers can make use of the recent technological advances in FinTech applications to reach out to consumers and manage their expectations directly without relying on the intermediation of the media (D'Acunto and Rossi (ming)), which might pollute policy messages through the lens of specific political views (Barone et al. (2015)). 


\section{References}

Andre, P., C. Pizzinelli, C. Roth, and J. Wohlfart (2019). Subjective models of the macroeconomy: Evidence from experts and a representative sample. Available at SSRN 3355356 .

Angeletos, G.-M. (2020). Discussion of communication and the beliefs ofeconomic agents. In Proceedings of the 2020 Economic Policy Symposium Proceedings.

Angeletos, G.-M. and K. A. Sastry (2018, December). Managing expectations: Instruments vs. targets. Working Paper 25404, National Bureau of Economic Research.

Armantier, O., S. Nelson, G. Topa, W. Van der Klaauw, and B. Zafar (2016). The price is right: Updating inflation expectations in a randomized price information experiment. Review of Economics and Statistics 98(3), 503-523.

Barone, G., F. D'Acunto, and G. Narciso (2015). Telecracy: Testing for channels of persuasion. American Economic Journal: Economic Policy 7(2).

Binder, C. (2017). Fed speak on main street: Central bank communication and household expectations. Journal of Macroeconomics 52, 238-251.

Binder, C. and A. Rodrigue (2018). Household informedness and long-run inflation expectations: Experimental evidence. Southern Economic Journal 85(2), 580-598.

Blinder, A. S. (2009). Talking about monetary policy: the virtues (and vice?) of central bank communication.

Blinder, A. S., M. Ehrmann, M. Fratzscher, J. De Haan, and D.-J. Jansen (2008). Central bank communication and monetary policy: A survey of theory and evidence. Journal of Economic Literature 46(4), 910-45.

Blinder, A. S. and A. B. Krueger (2004). What does the public know about economic policy, and how does it know it? Brookings Papers on Economic Activity (1), 327.

Brunner, K. (1981). The art of central banking. Graduate School of Management, University of Rochester.

Coibion, O., D. Georgarakos, Y. Gorodnichenko, and M. Weber (2020). Forward guidance and household expectations. Technical report, National Bureau of Economic Research.

Coibion, O., Y. Gorodnichenko, and M. Weber (2019). Monetary policy communications and their effects on household inflation expectations. Technical report, National Bureau of Economic Research.

Crump, R. K., S. Eusepi, A. Tambalotti, and G. Topa (2020). Subjective intertemporal substitution. FRB of New York Staff Report (734).

D'Acunto, F. (2020a). Identity and choice under risk. Working Paper.

D'Acunto, F. (2020b). Tear down this wall street: Anti-market rhetoric, motivated beliefs, and investment. Working Paper.

D'Acunto, F., A. Fuster, and M. Weber (2020). Do we need diverse policy committees? why? Working Paper.

D'Acunto, F., D. Hoang, M. Paloviita, and M. Weber (2019a). Cognitive abilities and inflation expectations. In AEA Papers and Proceedings, Volume 109, pp. 562-66.

D'Acunto, F., D. Hoang, M. Paloviita, and M. Weber (2019b). Human frictions in the transmission of economic policies. Working Paper.

D'Acunto, F., D. Hoang, M. Paloviita, and M. Weber (2020). Iq, expectations, and choice. Working Paper.

D'Acunto, F., D. Hoang, and M. Weber (2020). Managing households' expectations with unconventional policies. Technical report, National Bureau of Economic Research.

D'Acunto, F., U. Malmendier, J. Ospina, and M. Weber (2019). Exposure to daily price changes and inflation expectations. Technical report, National Bureau of Economic Research.

D'Acunto, F., U. Malmendier, and M. Weber (2020). Gender roles and the gender 
expectations gap. Technical report, National Bureau of Economic Research.

D'Acunto, F., M. Prokopczuk, and M. Weber (2018). Historical antisemitism, ethnic specialization, and financial development. The Review of Economic Studies 86(3), $1170-1206$.

D'Acunto, F., T. Rauter, C. Scheuch, and M. Weber (2020). Perceived precautionary savings motives: Evidence from fintech. Working Paper.

D'Acunto, F. and A. Rossi (forthcoming). Robo-advising. Handbook of Technological Finance.

De Quidt, J., J. Haushofer, and C. Roth (2018). Measuring and bounding experimenter demand. American Economic Review 108(11), 3266-3302.

Ehrmann, M. and M. Fratzscher (2009). Explaining monetary policy in press conferences. International Journal of Central Banking.

Farhi, E. and I. Werning (2019). Monetary policy, bounded rationality, and incomplete markets. American Economic Review 109(11), 3887-3928.

Fuster, A., R. Perez-Truglia, M. Wiederholt, and B. Zafar (2018). Expectations with endogenous information acquisition: An experimental investigation. Technical report, National Bureau of Economic Research.

Gabaix, X. (2020). A behavioral new keynesian model. American Economic Review 110(8), 2271-2327.

Goodfriend, M. (1986). Monetary mystique: Secrecy and central banking. Journal of Monetary Economics 17(1), 63-92.

Greider, W. (1989). Secrets of the temple: How the Federal Reserve runs the country. Simon and Schuster.

Grinblatt, M., M. Keloharju, and J. Linnainmaa (2011). IQ and stock market participation. The Journal of Finance 66 (6), 2121-2164.

Haldane, A., A. Macaulay, and M. McMahon (2020). The 3 e's of central bank communication with the public.

Haldane, A. and M. McMahon (2018). Central bank communications and the general public. In AEA Papers and Proceedings, Volume 108, pp. 578-83.

Kryvtsov, O. and L. Petersen (2020). Central bank communication that works: Lessons from lab experiments. Journal of Monetary Economics.

Lamla, M. J. and D. V. Vinogradov (2019). Central bank announcements: Big news for little people? Journal of Monetary Economics 108, 21-38.

Lange, J., B. Sack, and W. Whitesell (2003). Anticipations of monetary policy in financial markets. Journal of Money, Credit and Banking, 889-909.

Neuhierl, A. and M. Weber (2019). Monetary policy communication, policy slope, and the stock market. Journal of Monetary Economics 108, 140-155.

Swanson, E. T. Federal reserve transparency and financial market forecasts of short-term interest rates. In Journal of Money, Credit, and Banking. Citeseer.

Woodford, M. (2018). Monetary policy analysis when planning horizons are finite. NBER Macro Annual (forthcoming). 
Table 1: Descriptive Statistics

This table reports descriptive statistics of our survey sample. We define all variables and list the relevant data sources in Section II. We fielded the survey in June 2020.

\begin{tabular}{|c|c|c|c|c|c|c|c|c|}
\hline & Nobs & Mean & Std & $\mathrm{P} 25$ & $\mathrm{P} 50$ & P75 & & \\
\hline$E_{\text {prior }}^{i} \Delta$ income & 2,473 & -93.7 & 823.3 & -150.0 & 0.0 & 0.0 & & \\
\hline$E_{\text {posterior }}^{i} \Delta$ income & 2,441 & -186.2 & 779.9 & -387.5 & -25.0 & 125.0 & & \\
\hline$\left(\mathbb{E}_{\text {posterior }}^{i}-\mathbb{E}_{\text {prior }}^{i}\right) \Delta$ income & 2.44 & -92.6 & 802.5 & -271.9 & 0.0 & 125.0 & & \\
\hline Age & 2,476 & 40.4 & 10.0 & 32 & 41 & 49 & & \\
\hline \multirow[t]{2}{*}{ Log Income } & 2,149 & 8.5 & 0.7 & 8.2 & 8.6 & 8.9 & & \\
\hline & Nobs & 0 & 1 & 2 & 3 & 4 & 5 & 6 \\
\hline Married & 2,486 & 1,366 & 1,120 & & & & & \\
\hline Unemployed & 2,486 & 2,338 & 138 & & & & & \\
\hline Has Kids & 2,334 & 826 & 1,508 & & & & & \\
\hline Urban & 2,471 & 279 & 2,192 & & & & & \\
\hline Lives in Helsinki & 2,476 & 1,649 & 827 & & & & & \\
\hline College Degree & 2,255 & 1,227 & 1,028 & & & & & \\
\hline Grocery Shopper & 2,254 & 1,343 & 911 & & & & & \\
\hline Financial Decision Maker & 2,436 & 50 & 2,386 & & & & & \\
\hline Fin. Literacy & 2,381 & 810 & 1,571 & & & & & \\
\hline Risk Tolerance & 2,436 & 1,409 & 1,027 & & & & & \\
\hline Has a Rainy-Day Fund & 2,486 & 876 & 1,610 & & & & & \\
\hline Policy Awareness & 2,486 & 1,801 & 685 & & & & & \\
\hline Benefit Households & 2,462 & 431 & 513 & 517 & 579 & 308 & 82 & 32 \\
\hline
\end{tabular}


Table 2: Forecast Revision for Household Income After Policy Communication: Target vs. Instrument Communication

This table reports the average treatment effects of providing subjects randomly with different forms of policy communication on the forecast revisions for subjects' household monthly income relative to a control group of subjects who did not receive any information about economic policies. Columns (1) and (2) report the results for target communication, which was a tweet by Bank of Finland Governor Olli Rehn that the "The European Central Bank will do whatever is necessary to minimize the financial damage to citizens caused by the corona crisis." Columns (3) and (4) report the results for instrument communication, which was a tweet by Bank of Finland Governor Olli Rehn that the "New Euro 750 billion Pandemic Emergency Programme (PEPP) launched by the European Central Bank." We fielded the survey in June 2020.

\begin{tabular}{|c|c|c|c|c|}
\hline \multirow{3}{*}{$\begin{array}{l} \\
\text { Treated with } \\
\text { Communication }\end{array}$} & \multicolumn{2}{|c|}{$\begin{array}{c}\text { Target } \\
\text { Communication }\end{array}$} & \multicolumn{2}{|c|}{$\begin{array}{c}\text { Instrument } \\
\text { Communication }\end{array}$} \\
\hline & $(1)$ & $(2)$ & $(3)$ & $(4)$ \\
\hline & $\begin{array}{r}75.0 * \\
(40.9)\end{array}$ & $\begin{array}{r}82.7 * \\
(45.1)\end{array}$ & $\begin{array}{c}62.5 \\
(40.4)\end{array}$ & $\begin{array}{c}39.2 \\
(45.8)\end{array}$ \\
\hline Age & & $\begin{array}{l}-3.9 \\
(21.0)\end{array}$ & & $\begin{array}{l}-0.8 \\
(21.1)\end{array}$ \\
\hline $\mathrm{Age}^{2}$ & & $\begin{array}{c}0.1 \\
(0.3)\end{array}$ & & $\begin{array}{c}-0.0 \\
(0.3)\end{array}$ \\
\hline Married & & $\begin{array}{l}-1.3 \\
(53.5)\end{array}$ & & $\begin{array}{c}76.6 \\
(54.2)\end{array}$ \\
\hline Log Income & & $\begin{array}{c}59.9 \\
(49.3)\end{array}$ & & $\begin{array}{c}19.9 \\
(49.6)\end{array}$ \\
\hline Unemployed & & $\begin{array}{c}134.2 \\
(110.6)\end{array}$ & & $\begin{array}{l}151.2 \\
(90.0)\end{array}$ \\
\hline Has Kids & & $\begin{array}{l}-19.4 \\
(51.7)\end{array}$ & & $\begin{array}{c}-49.5 \\
(49.5)\end{array}$ \\
\hline Urban & & $\begin{array}{c}18.2 \\
(51.7)\end{array}$ & & $\begin{array}{c}71.6 \\
(49.7)\end{array}$ \\
\hline Lives in Helsinki & & $\begin{array}{r}-89.0 \\
(52.5)\end{array}$ & & $\begin{array}{c}-125.3 * * * \\
(53.7)\end{array}$ \\
\hline College Degree & & $\begin{array}{c}-77.9 \\
(50.8)\end{array}$ & & $\begin{array}{c}-42.0 \\
(51.0)\end{array}$ \\
\hline Grocery Shopper & & $\begin{array}{c}10.6 \\
(55.5)\end{array}$ & & $\begin{array}{l}-0.7 \\
(55.6)\end{array}$ \\
\hline Financial Decision Maker & & $\begin{array}{c}-515.4 * * \\
(247.53)\end{array}$ & & $\begin{array}{l}-73.7 \\
(271.5)\end{array}$ \\
\hline Fin. Literacy & & $\begin{array}{c}5.7 \\
(52.5)\end{array}$ & & $\begin{array}{r}-90.5 * \\
(53.3)\end{array}$ \\
\hline Risk Tolerance & & $\begin{array}{c}1.0 \\
(50.0)\end{array}$ & & $\begin{array}{c}1.3 \\
(48.1)\end{array}$ \\
\hline Has a Rainy-Day Fund & & $\begin{array}{c}-30.4 \\
(50.1)\end{array}$ & & $\begin{array}{c}44.8 \\
(50.5)\end{array}$ \\
\hline Constant & $\begin{array}{c}-137.2 * * * \\
(30.9)\end{array}$ & $\begin{array}{l}-74.2 \\
(548.7)\end{array}$ & $\begin{array}{c}-137.2 * * * \\
\quad(30.9)\end{array}$ & $\begin{array}{c}-149.1 \\
(571.1)\end{array}$ \\
\hline $\mathrm{R}^{2}$ & 1,633 & 1,166 & 1,660 & 1,191 \\
\hline Nobs & 0.002 & 0.022 & 0.001 & 0.015 \\
\hline
\end{tabular}




\section{Table 3: Forecast Revision for Annual Income: Target Communication by IQ}

This table reports the average treatment effects of providing subjects randomly with target policy communication on the forecast revisions for subjects' household monthly income relative to a control group of subjects who did not receive any information about economic policies. Columns (1) and (2) report the results for target communication, which was a tweet by Bank of Finland Governor Olli Rehn that the "The European Central Bank will do whatever is necessary to minimize the financial damage to citizens caused by the corona crisis." Columns (3) and (4) report the results for instrument communication, which was a tweet by Bank of Finland Governor Olli Rehn that the "New Euro 750 billion Pandemic Emergency Programme (PEPP) launched by the European Central Bank." We fielded the survey in June 2020.

\begin{tabular}{lcccc}
\hline & \multicolumn{2}{c}{ Target Communication } & \multicolumn{2}{c}{ Target Communication } \\
& \multicolumn{2}{c}{ Below-Median IQ } & & Above-Median IQ \\
\cline { 2 - 3 } & $(1)$ & $(2)$ & $(3)$ & $(4)$ \\
\hline Treated with & $95.0^{*}$ & $163.6^{* * *}$ & 63.4 & 53.4 \\
Communication & $(50.8)$ & $(63.6)$ & $(47.1)$ & $(51.0)$ \\
& & & & $\mathrm{X}$ \\
Controls in Table 2 & $\mathrm{X}$ & $\mathrm{X}$ & $\mathrm{X}$ & \\
$\mathrm{R}^{2}$ & & & & 0.026 \\
Nobs & 0.002 & 0.030 & 0.001 & 974 \\
\hline
\end{tabular}




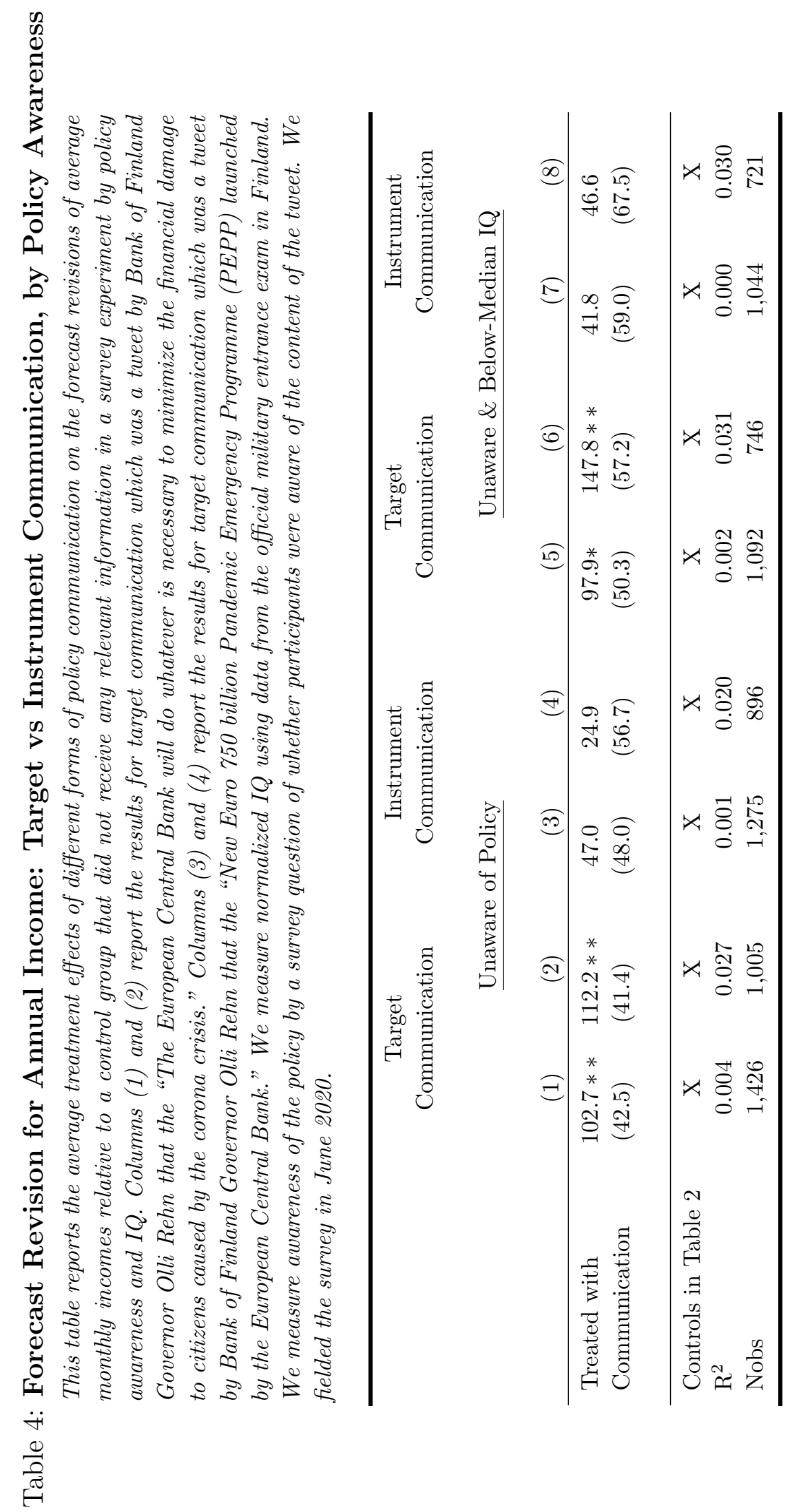


Table 5: Forecast Revision for Annual Income: Target Communication by Prior Income Expectations \& IQ

This table reports the average treatment effects of target communication on the forecast revisions of average monthly incomes relative to a control group that did not receive any relevant information in a survey experiment by prior income expectations IQ. The target communication which was a tweet by Bank of Finland Governor Olli Rehn that the "The European Central Bank will do whatever is necessary to minimize the financial damage to citizens caused by the corona crisis." We split the sample by the median prior income expectations and measure normalized $I Q$ using data from the official military entrance exam in Finland. We fielded the survey in June 2020.

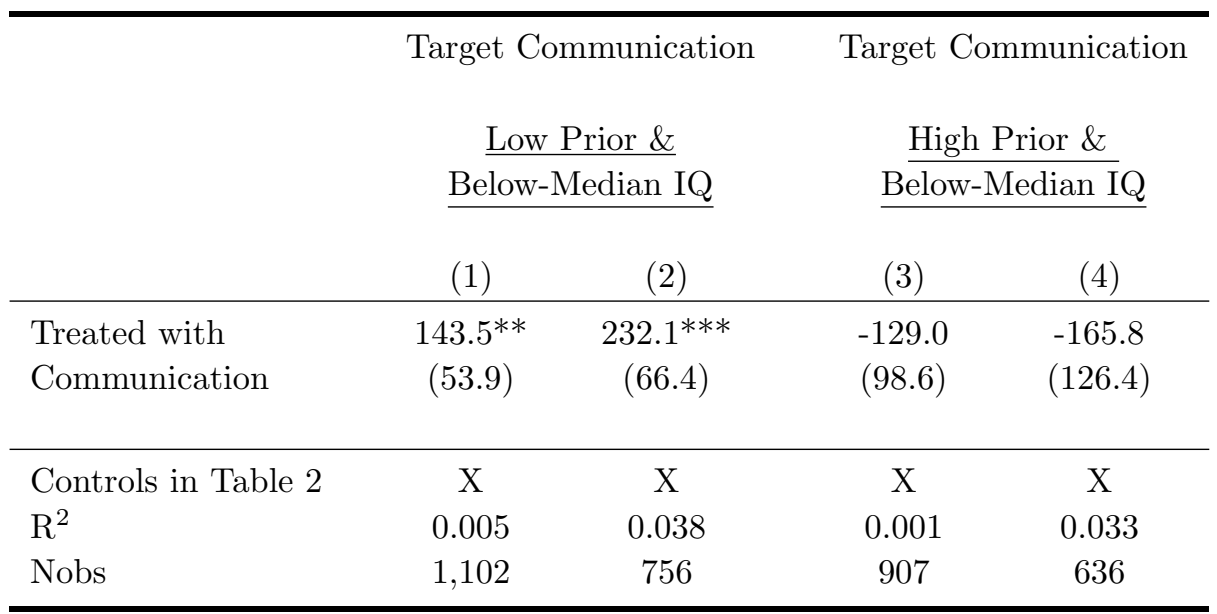


Online Appendix:

\section{Effective Policy Communication: Target versus Instrument}

Francesco D'Acunto, Daniel Hoang, Maritta Paloviita, and Michael Weber 


\section{Survey Questions}

We now report the survey questions we fielded translated to English. The survey starts with a short introductory statement.

Welcome to the Bank of Finland Survey on Consumer Expectations and Economic Prospects during the current corona crisis!

In the survey, we ask about your perceptions of the current economic situation, your personal outlook and how the current Corona virus crisis affects your overall view of the economy, if at all. The responses are used to better understand the concerns and needs of the Finnish population, support policy-making, and ensure efficient and effective policy responses.

No special knowledge is required, and there are no right or wrong answers to the survey. It is important for us that you state your own opinion, not others' opinions, so please do not consult with others or look for external sources of information. Any answer is correct as long as it truly reflects your opinion!

Question 1 How large is the size of your household, i.e. the group of people who live together with you, including you?

Dropdown menu 1 to 10 or more

If $\mathrm{Q} 1>1$

Question 2 How many children and teenagers under 18 years old are there in your household?

Dropdown menu 1 to 10 or more

Question 3 Have you set aside emergency or rainy day funds that would cover your expenses for 3 months in case of sickness, job loss, economic downturn, or other emergencies?

- Yes

- No

If $\mathrm{Q} 3=\mathrm{No}$ 
Question 4 If you were to lose your main source of income (e.g. job, government benefits), do you think you could cover your expenses for 3 months by borrowing money, using savings, selling assets, or borrowing from friends/family?

- Yes

- No

Question 5 Does your household have total savings and financial investments (excluding real estate investments, like your house or rental property) worth more than one month of combined household income?

- Yes

- No

If $\mathrm{Q} 5=$ Yes

Question 6 Please indicate your best guess as to what percentage of your savings and financial wealth you invest in the following categories (excluding real estate investments, like your house or rental property). Put "0" if you do not invest in a given category.

- Cash and bank deposits ... percent

- Stocks and mutual funds ... percent

- Private pension plans and life insurance policies ... percent

- Cryptocurrencies such as Bitcoin ... percent

- Other ... percent

Question 7 Approximately how much did your household make in total gross income per month in the last year (2019)? (Please include retirement income, entrepreneurial income, student allowance, unemployment benefits, rental income, child allowances, dividends, etc.)

... EUR per month

Question 8 Do you think your household's average total gross income per month will increase or decrease in 2020 relative to 2019 ?

- Increase 
- Decrease

- Unchanged

If Q8 = Increase

Question 9 Do you think your household's average total gross income per month will increase or decrease in 2020 relative to 2019 ?

... EUR higher per month

If $\mathrm{Q} 8=$ Increase

Question 10 How much lower do you think your household's average total gross income per month will be in 2020 relative to 2019?

... EUR lower per month

Question 11 Do you currently have a paid job and/or run your own business?

- Yes

- No

If $\mathrm{Q} 11=\mathrm{No}$

Question 12 Are you actively looking for a job and/or to start your own business?

- Yes

- No

Question 13 What is your best guess about what the current unemployment rate is in Finland, and what do you think the unemployment rate will be in the future?

- Unemployment rate today (May 2020): ... \%

- Unemployment rate one year from today (in May 2021): ... \%

- Unemployment rate five years from today (in May 2025): .. \% \%

Question 14 What do you think is today's interest rate on a new 20-year adjustable rate mortgage for someone with excellent credit, and what do you think will be the rate for that mortgage in the future? 
- Current rate? (May 2020): ... \%

- Rate one year from today (in May 2021): ... \%

- Rate five years from today (in May 2025): ... \%

We would like to ask you about the rate of inflation/deflation

Note: Inflation is the percentage rise in prices in the economy, most commonly measured by the Consumer Price Index. Deflation means prices are falling, and hence there will be a decrease in prices going forward. For instance, if a price moves from 1 Euro to 1.02 Euros the rate of inflation is $(1.05-1) / 1=2 \%$. If a price moves from 1 Euros to 0.98 Euros the rate of deflation is $(0.98-1) / 1=-2 \%)$.

Question 15 Over the next 12 months, do you think that price level will increase (inflation), decrease (deflation), or stay the same (no change)?

- Increase

- Decrease

- Stay the same

If $\mathrm{Q} 15=$ Increase

Question 16 What is your best guess about the rate of inflation over the next 12 months?

... \% per year

If $\mathrm{Q} 15=$ Decrease

Question 17 What is your best guess about the rate of deflation over the next 12 months?

... \% per year

If $\mathrm{Q} 15=$ Stay the same

Question 18 What is your best guess about the rate of inflation/deflation over the next 12 months?

$\ldots \%$ per year

Question 19 How confident are you in this answer? 
[Slider from 1 to 7 with 1 Absolutely confident and 7 Absolutely unconfident] INFORMATION TREATMENTS.

We have just a few more questions. But before you give us your responses, we would like to provide you with some information. We will subsequently ask you again about your expectations again. We are interested to see if this information will change your expectations or not. There is no right or wrong reaction: Whether this information changes your expectations or not is solely determined by your opinions, and any reaction or non-reaction is right as long as it reflects what you truly believe. The European Central Bank that is responsible for monetary policy in the whole Eurozone including Finland and the Finnish Financial and Insurance Supervisory Authority have recently implemented several policy measures.

Control Group:

Bank of Finland Governor Rehn tweeted on January $20^{\text {th }}$ :

The January engagement created the spirit of Winter War 80 years ago. Memories do not live, but they do.

Treatment Group Target Communication:

Bank of Finland Governor Rehn tweeted on March 20 ${ }^{\text {th }}$ :

The European Central Bank will do whatever is necessary to minimize the financial damage to citizens caused by the corona crisis.

Treatment Group Instrument Communication:

Bank of Finland Governor Rehn tweeted on March $18^{\text {th }}$ :

New EUR750 billion Pandemic Emergency Programme (PEPP) launched by the European Central Bank.

Question 20 Were you aware of the information

[Slider from 1 to 7 with 1 Totally unaware and 7 Totally aware]

Question 21 How much do you think Finnish households might benefit from the recent policy actions?

[Slider from 1 to 7 with 1 will not benefit at all to 7 will benefit extremely]

Now we would like to ask you again about the rate of inflation/deflation. 
Question 22 In THIS question, you will be asked about the PERCENT CHANCE of something happening. The percent chance must be a number between 0 and 100 and the sum of your answers must add up to 100. For example, numbers like:

Between 2 and 5 percent may indicate "almost no chance" 18 percent or so may mean "not much chance" Between 47 and 52 percent chance may be a "pretty even chance" 83 percent or so may mean a "very good chance" Between 95 and 98 percent chance may be "almost certain"

What do you think is the percent chance that, over the next 12 months

- the rate of inflation will be $12 \%$ or more

- the rate of inflation will be between $8 \%$ and $12 \%$

- the rate of inflation will be between $4 \%$ and $8 \%$

- the rate of inflation will be between $2 \%$ and $4 \%$

- the rate of inflation will be between $0 \%$ and $2 \%$

- the rate of deflation (opposite of inflation) will be between $0 \%$ and $2 \%$

- the rate of deflation (opposite of inflation) will be between $2 \%$ and $4 \%$

- the rate of deflation (opposite of inflation) will be between $4 \%$ and $8 \%$

- the rate of deflation (opposite of inflation) will be between $8 \%$ and $12 \%$

- the rate of deflation (opposite of inflation) will be $12 \%$ or more

Question 23 What do you think is the percent chance that your household's monthly total gross income will change by the following amounts on average over the next twelve months compared to the last twelve months? Based on your answer to question 7, your average monthly gross income in 2019 was approximately XX Euros (Note to programmer: please report answer to question 7). For example, numbers like:

Between 2 and 5 percent may indicate "almost no chance" 18 percent or so may mean "not much chance" Between 47 and 52 percent chance may be a "pretty even chance" 83 percent or so may mean a "very good chance" Between 95 and 98 percent chance may be "almost certain" What do you think is the percent chance that, over the next 12 months your total average monthly household gross income... 
- will fall by more than EUR 3.000

- will fall between EUR 2.500 and EUR 3.000

- will fall between EUR 2.000 and EUR 2.500

- will fall between EUR 1.500 and EUR 2.000

- will fall between EUR 1.000 and EUR 1.500

- will fall between EUR 500 and EUR 1.000

- will fall between EUR 250 and EUR 500

- will fall between EUR 0 and EUR 250

- will rise between EUR 0 and EUR 250

- will rise between EUR 250 and EUR 500

- will rise between EUR 500 and EUR 1.000

- will rise between EUR 1.000 and EUR 1.500

- will rise between EUR 1.500 and EUR 2.000

- will rise between EUR 2.000 and EUR 2.500

- will rise between EUR 2.500 and EUR 3.000

- will rise by more than EUR 3.000

Question 24 We would like to ask you again what is your best guess about what the current unemployment rate is in Finland, and what do you think the unemployment rate will be in the future?

- Unemployment rate today (May 2020): .. \%

- Unemployment rate one year from today (in May 2021): ... \%

- Unemployment rate five years from today (in May 2025): . . \%

Question 25 What do you think is today's interest rate on a new 20-year adjustable rate mortgage for someone like you, and what do you think will be the rate for that mortgage in the future?

- Current rate? (May 2020): ... \%

- Rate one year from today (in May 2021): ... \%

- Rate five years from today (in May 2025): ... \%

Question 26 Who typically does the grocery shopping in your household? (Please select one)

- I do almost all of the grocery shopping for my household 
- I share the grocery shopping rather equally with somebody else in my household

- I almost never do the grocery shopping for my household

Now, we would like to ask your opinions about the value of money over time.

Question 27 Let's say you have EUR200 in a savings account. The account earns 10\% interest per year. If you never withdraw money or interest payments, how much will you have in the account at the end of 2 years?

$\ldots$ EUR

Question 28 Which of the following best describes how financial decisions are made in your household?

- Someone else in my household makes most financial decisions

- I share financial decisions equally with someone else in my household

- I make almost all financial decisions myself

Question 29 On a scale from 1 to $\%$, how would you rate your willingness to take risks regarding financial matters?

[Slider from 1 to 7 with 1 Not willing at all and 7 Very willing] 
Figure A.1: Policy Benefits Households: Target versus Instrument Communication by IQ

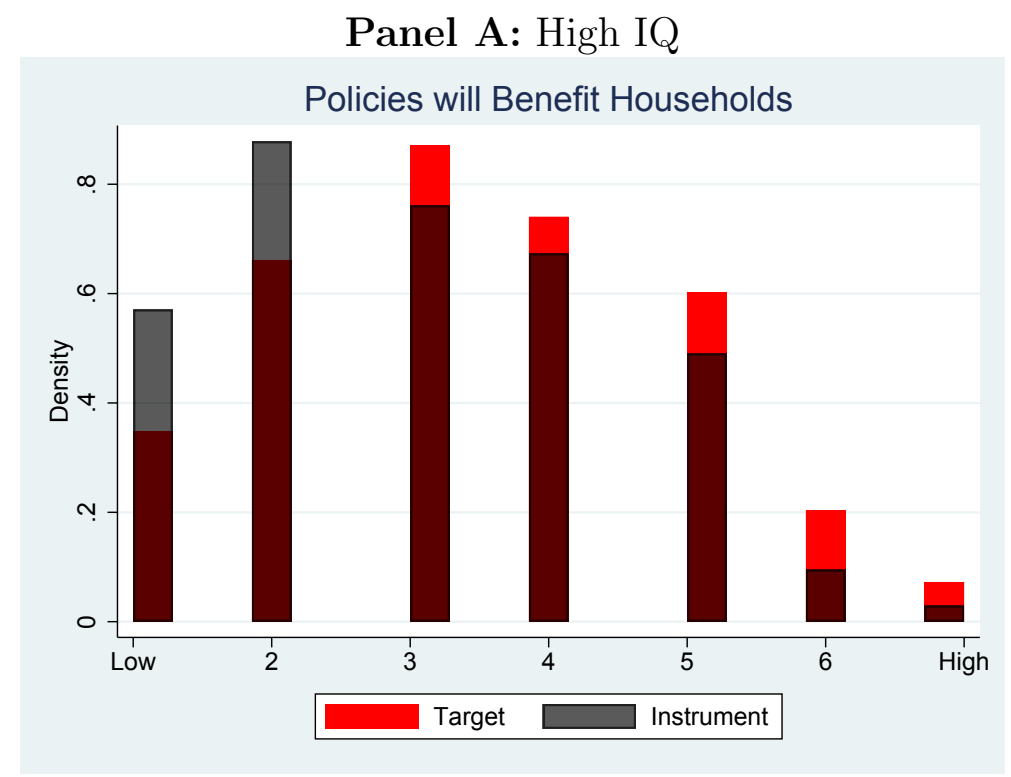

Panel B: Low IQ

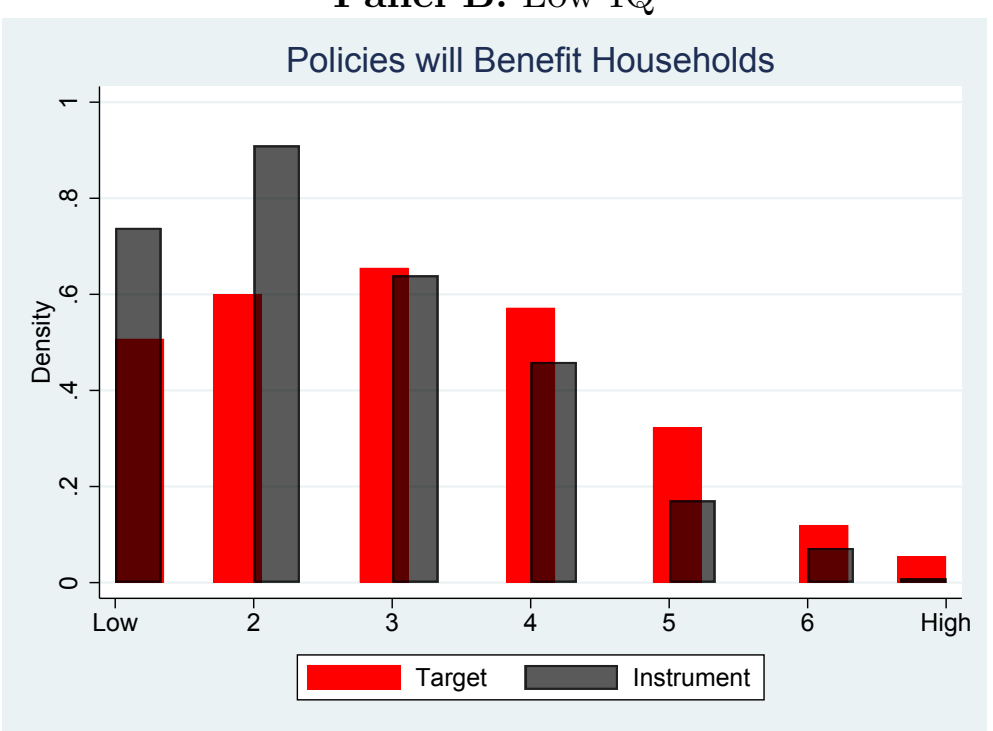

This figure plots the density of whether target and instrument communication benefit households in a survey experiment by IQ. Target communication was a tweet by Bank of Finland Governor Olli Rehn that the "The European Central Bank will do whatever is necessary to minimize the financial damage to citizens caused by the corona crisis." Instrument communication which was a tweet by Bank of Finland Governor Olli Rehn that the "New Euro 750 billion Pandemic Emergency Programme (PEPP) launched by the European Central Bank." We measure normalized IQ using data from the official military entrance exam in Finland. We elicit whether policies benefit households on a seven-point Likert scale with 7 being policies benefit households extremely. We fielded the survey in June 2020. 
Figure A.2: Posterior Expected Income Change Across Treatment \& by IQ

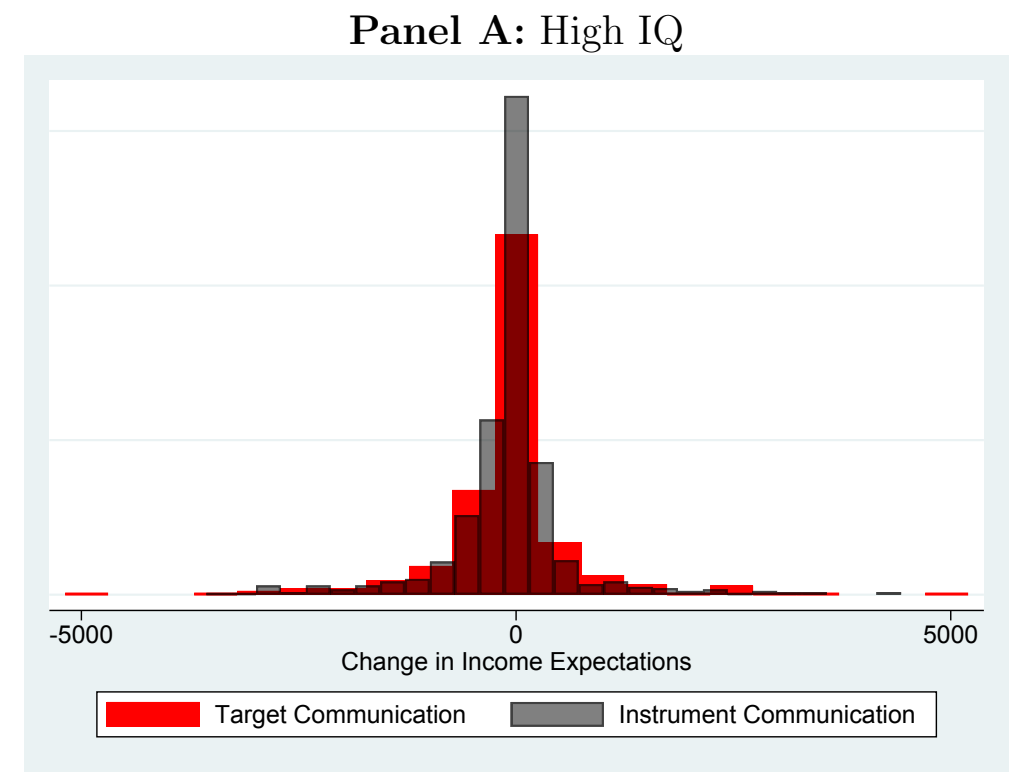

Panel B: Low IQ

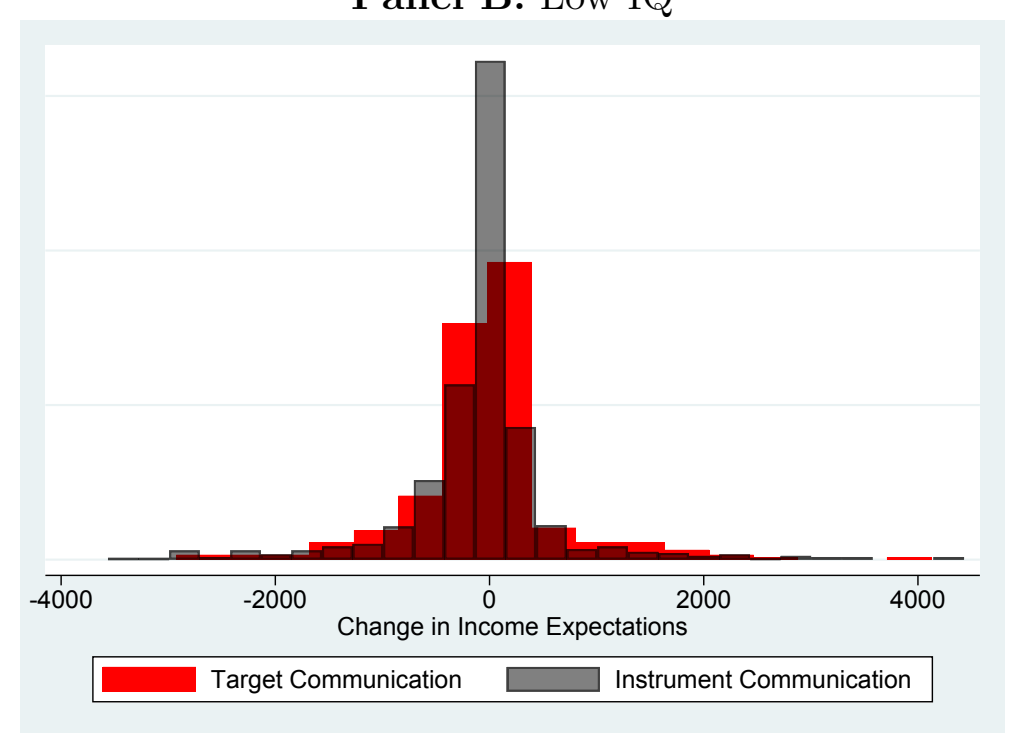

This figure plots the change in expected income changes by different forms of policy communication by IQ. Target communication was a tweet by Bank of Finland Governor Olli Rehn that the "The European Central Bank will do whatever is necessary to minimize the financial damage to citizens caused by the corona crisis." Instrument communication which was a tweet by Bank of Finland Governor Olli Rehn that the "New Euro 750 billion Pandemic Emergency Programme (PEPP) launched by the European Central Bank." We measure normalized $I Q$ using data from the official military entrance exam in Finland. We elicit whether policies benefit households on a seven-point Likert scale with 7 being policies benefit households extremely. We fielded the survey in June 2020. 
Table A.1: Descriptive Statistics by Treatment Arm

This table reports descriptive statistics of our survey sample by treatment arms and control group. We define all variables and list the relevant data sources in Section II. We fielded the survey in June 2020.

\begin{tabular}{|c|c|c|c|c|c|c|c|c|c|}
\hline & \multicolumn{3}{|c|}{ Control } & \multicolumn{3}{|c|}{ Target } & \multicolumn{3}{|c|}{ Instrument } \\
\hline & Nobs & Mean & Std & Nobs & Mean & Std & Nobs & Mean & Std \\
\hline$E_{\text {prior }}^{i} \Delta$ income & 865 & -92.2 & 846 & 792 & -123.9 & 838.1 & 816 & -66.2 & 783.3 \\
\hline$E_{\text {posterior }}^{i} \Delta$ income & 853 & -232.1 & 817.5 & 781 & -182.2 & 787 & 807 & -141.5 & 728.9 \\
\hline$\left(\mathbb{E}_{\text {posterior }}^{i}-\mathbb{E}_{\text {prior }}^{i}\right) \Delta$ income & 853 & -137.2 & 901.9 & 780.0 & -62.2 & 748.2 & 807 & -74.8 & 738.0 \\
\hline Age & 864 & 40.1 & 10.2 & 795 & 40.6 & 9.7 & 817 & 40.5 & 9.9 \\
\hline \multirow[t]{2}{*}{ Log Income } & 743 & 8.5 & 0.7 & 697 & 8.5 & 0.7 & 709 & 8.5 & 0.7 \\
\hline & Nobs & $0[\%]$ & $1[\%]$ & Nobs & $0[\%]$ & $1[\%]$ & Nobs & $0[\%]$ & $1[\%]$ \\
\hline Married & 868 & 56.2 & 43.8 & 799 & 55.6 & 44.4 & 819 & 53.0 & 47.0 \\
\hline Unemployed & 864 & 93.8 & 6.3 & 795 & 95.1 & 4.9 & 817 & 94.5 & 5.5 \\
\hline Has Kids & 811 & 35.9 & 64.1 & 754 & 35.5 & 64.5 & 769 & 34.7 & 75.3 \\
\hline Urban & 862 & 10.6 & 89.4 & 793 & 12.2 & 87.8 & 816 & 11.2 & 88.9 \\
\hline Lives in Helsinki & 864 & 66.7 & 33.3 & 795 & 65.4 & 34.6 & 817 & 67.7 & 32.3 \\
\hline College Degree & 788 & 56.0 & 44.0 & 725 & 53.4 & 46.6 & 742 & 53.8 & 46.2 \\
\hline Grocery Shopper & 788 & 57.5 & 42.5 & 713 & 59.8 & 40.3 & 753 & 61.6 & 38.4 \\
\hline Financial Decision Maker & 850 & 2.6 & 97.4 & 779 & 1.5 & 98.5 & 807 & 2.0 & 98.0 \\
\hline Fin. Literacy & 821 & 32.8 & 67.2 & 767 & 35.3 & 64.7 & 793 & 34.1 & 66.0 \\
\hline Risk Tolerance & 850 & 58.8 & 41.2 & 779 & 56.5 & 43.5 & 807 & 58.12 & 41.9 \\
\hline Has a Rainy-Day Fund & 868 & 37.1 & 62.9 & 799 & 33.4 & 66.6 & 819 & 35.0 & 532.0 \\
\hline
\end{tabular}




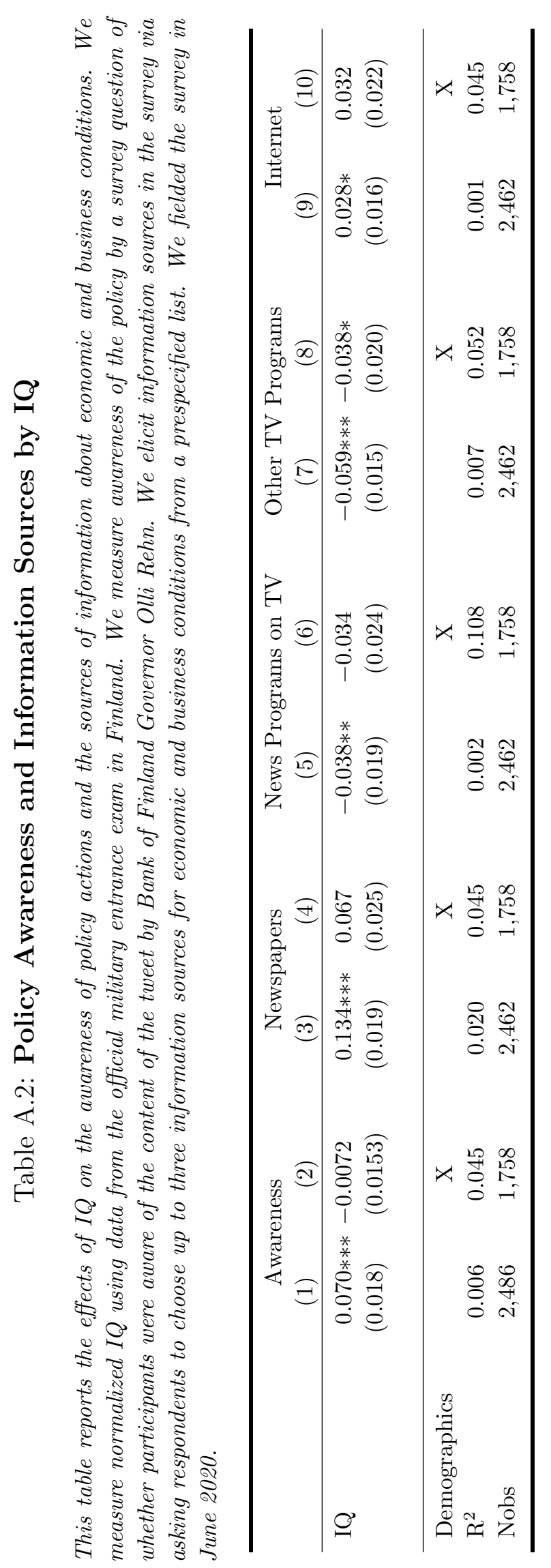




\section{Working Paper Series in Economics}

recent issues

No. 147 Francesco D'Acunto, Daniel Hoang, Maritta Paloviita and Michael Weber: Effective policy communication: Targets versus instruments, March 2021

No. 146 Jörg Urban: Credit cycles revisited, November 2020

No. 145 Dávid Burka, Clemens Puppe, László Szepesváry and Atilla Tasnádi: Voting: a machine learning approach, November 2020

No. 144 Guanhao Li, Clemens Puppe and Arkadii Slinko: Towards a classification of maximal peak-pit Condorcet domains, September 2020

No. 143 Andranik S. Tangian: Using composite indicators in econometric decision models with application to occupational health, September 2020

No. 142 Ingrid Ott and Susanne Soretz: Institutional design and spatial (in)equality - the Janus face of economic integration, August 2020

No. 141 Laura Reh, Fabian Krüger and Roman Liesenfeld: Predicting the global minimum variance portfolio, July 2020

No. 140 Marta Serra Garcia and Nora Szech: Understanding demand for COVID-19 antibody testing, May 2020

No. 139 Fabian Krüger and Lora Pavlova: Quantifying subjective uncertainty in survey expectations, March 2020

No. 138 Michael Müller and Clemens Puppe: Strategy-proofness and responsiveness imply minimal participation, January 2020

No. 137 Andranik S. Tangian: Tackling the Bundestag growth by introducing fraction-valued votes, October 2019 